Article

\title{
Rethinking Participation in Smart Energy System Planning
}

\author{
Imke Lammers * (D) and Maarten J. Arentsen \\ Department of Governance and Technology for Sustainability (CSTM), University of Twente; \\ Enschede 7500 AE, The Netherlands; m.j.arentsen@utwente.nl \\ * Correspondence: i.lammers@utwente.nl; Tel.: +31-53-489-4540
}

Received: 3 October 2017; Accepted: 24 October 2017; Published: 26 October 2017

\begin{abstract}
While the technical layout of smart energy systems is well advanced, the implementation of these systems is slowed down by the current decision-making practice regarding such energy infrastructures. We call for a reorganisation of the decision-making process on local energy planning and address the question 'how can decision-making on the design and implementation of Smart Energy Systems be accelerated?' Inspired by engineering design thinking and based on two workshop sessions, we identify five design phases and an implementation phase, and distinguish between a design component and a participation component. This allows for the effective participation of external stakeholders at four specific moments in the decision-making process. This way, efficiency and effectiveness in smart energy system planning can be increased, without compromising on participation. When applied to the Dutch context of energy planning, the developed decision-making model is useful for project participants as well as policy-makers in a wide variety of settings.
\end{abstract}

Keywords: smart energy system; participation; decision-making process; design; energy planning

\section{Introduction}

Smart grids are considered an important backbone of the Dutch energy transition by the Dutch government [1] as well as by a consultancy agency on renewable energy systems [2]. Smart grids are assumed to facilitate the downscaling of energy production via distributed generation (DG), efficient integration, and load management of many different sustainable energy technologies, ranging from heat pumps to the real-time remote control of electric vehicles and appliances [3]. Looking beyond smart (electricity) grids, smart energy systems can facilitate the effective and efficient management of all innovative sustainable energy technologies and appliances available today. In smart energy systems, "smart electricity, thermal and gas grids are combined and coordinated to identify synergies between them in order to achieve an optimal solution for each individual sector as well as for the overall energy system" [4] (p. 1). Despite the assumed high sustainability potential, the implementation of smart energy systems is still predominantly rhetoric instead of practiced.

Looking at the current practice of energy planning in Dutch infrastructure projects (in the context of renovation and new construction), many projects start with high sustainability ambitions, but quite often end up with compromised outcomes [5]. The costs are significant, since decision-making takes lots of time and outcomes are not really supportive of the ambitions for the energy transition. This raises the question of how to improve the current practice of sustainable energy planning. The Dutch government recognises that the speed and quality of decision-making on energy projects need to increase [6]. To achieve this goal, more and earlier participation by all potential stakeholders is recommended by the Dutch government. In this article, we argue that there is indeed room for improvement in current Dutch energy planning practices, but that merely increasing participation will not lead to faster and higher quality outcomes. In our view, improving decision-making in 
energy planning is not merely a matter of more participation, but rather of a better-structured and focused participation.

Current literature on smart energy system design does not address this aspect of decision-making among stakeholders for the implementation of smart energy systems, as the following examples show. Current decision-making frameworks and support tools focus on entirely different aspects, like the development and application of algorithms for renewable energy systems [7-10], the general technical architecture [11], or energy efficiency measures in individual buildings [12,13]. While these technical aspects are important, all components have to be implemented by stakeholders in practice. This calls for collective decision-making between stakeholders. However, the current Dutch practice of consensus-seeking by actors with vested interests slows down progress and leads to compromised results [5]. For the design and implementation of highly complex smart energy systems in particular, this current decision-making approach is not suitable.

We therefore argue for the need to re-design the decision-making process on local energy planning. This will help to rebalance stakeholder participation and efficiency in decision-making on local sustainable energy infrastructures, in particular smart energy systems. Our goal is to make the decision-making process more organised and structured (and thereby accelerate it) while ensuring participation. This rebalance is needed for realising the Dutch energy transition and more specifically for increasing the speed and quality of decision-making on the implementation of smart renewable energy technologies. This article, therefore, addresses and answers the following question: how can decision-making on the design and implementation of smart energy systems be accelerated?

We will answer the question as follows. In Section 2, we analyse in more detail the current practice of local energy planning in the Netherlands. We conclude that under current practice, the design of a potential smart sustainable solution is often overshadowed by what the (interest-oriented) decision-making process generates as a feasible solution. Additionally, no distinction is made between the design and realisation of smart sustainable energy solutions. In Section 3, we therefore take the distinction between 'design' and 'implementation' of smart energy systems as the starting point for developing our alternative decision-making approach. This distinction has been inspired by the rational approach of engineering design practice [14]. In a typical engineering approach, the problem is analysed, a set of design principles (functionalities) is formulated, possible solutions are designed, possibly tested and compared, and then the implementation of the design commences [14]. Inspired by this approach, we argue that the optimal technical design of a sustainable smart energy system entails a design component and a participation component. Section 4 specifies the methodology of workshop sessions for the creation and validation of our suggested approach. The resulting decision-making model for the design and implementation of smart energy systems is presented in Section 5. It should be noted that our approach is about decision-making as an act to attain results and not about the results (smart energy systems) themselves. Finally, Section 6 summarises and discusses the major findings of the article.

\section{Current Dutch Decision-Making Practices on Energy}

Following the liberalisation of energy markets in Europe, the institutional and technical outlook of the energy system underwent major changes. Among other aspects, the "vertical integration slowly eroded into an unbundled value chain with hybrid modes of organisation and diffuse property rights structures" [15] (p. 7). This also affected energy planning in the Netherlands. Under the old system, the integrated energy company was in charge of rolling out the energy infrastructure in residential areas. The options were rather straightforward: electricity and natural gas grid connections. In the mid-1990s, heat distribution was considered and implemented in several urban areas, but that was it. In the following years, the technical options for local energy infrastructures increased tremendously, whereas at the same time, the local responsibilities and division of tasks in energy infrastructure planning and implementation blurred. Moreover, decision-making on local energy planning became crowded due to an increase in the number of stakeholders involved: "the emergence 
of new actors and actor constellations in the dissemination of sustainable energy technologies has made local energy policy and planning more complex" [16] (p. 54). The old energy company split up into at least two independent companies: energy production/supply and distribution operator. The number of experts increased with the rise of available sustainable technical options and energy communities gave the local community a voice in the process [17]. The importance of local communities is also highlighted in a recent Dutch legal experiment (Crown Decree) that puts associations in charge of local electricity grids, as studied for a legal [18] and governance perspective [19].

The increased diversity in technological options and stakeholders was not accompanied by a new formalised institutional environment with clear rules on tasks, duties, and responsibilities. Such rules are crucial for the organisation of future electricity systems, as Verbong et al. [20] emphasise. However, Wolsink [21] explains that "there remains a complete lack of understanding of the need for institutional change required to establish [smart grids]" (p. 833). Decision-making on local energy planning, therefore, became a process of localised 'muddling through' with undefined, unpredictable outcomes. In line with the Dutch 'polder model' of consensus decision-making [22], many stakeholders sit around the table discussing smart energy options with democracy dominating the process on account of efficiency. Efficiency through faster decision-making is needed, though, as the Netherlands is lagging behind other European Union countries in achieving its renewable energy ambitions [23]. Several initiatives to improve decision-making in energy planning processes have been implemented over the last years, as described below.

\subsection{Elverding Advisory Committee}

In 2008, the Dutch government established an advisory committee for accelerating decision-making on infrastructure projects (the so-called 'Elverding' advisory committee) to investigate the causes for the delays in large infrastructure projects. The report states that "the demand of our [Dutch] consensus culture to combine the almost incompatible fails in many cases due to administrative and political incapacity to make decisions and to execute decisions once they have been made" (Translation from Dutch by the authors. Original Dutch text: "De behoefte in onze consensuscultuur om het bijna onverenigbare toch te verenigen, strandt vervolgens in veel gevallen op bestuurlijk en politiek onvermogen om besluiten te nemen en een eenmaal genomen besluit ook door te zetten.") [5] (p. 4). The indecisiveness and lengthy procedures eventually led to a loss in quality of the projects. Moreover, the decision-making process was also responsible for causing project delays due to the fact that it was not sufficiently well structured. To alleviate this barrier and achieve "faster and better decision-making", the committee recommends structuring the process into three phases: exploration, plan elaboration, and execution. The committee also recommended earlier and greater involvement of stakeholders at the start of the exploration phase, by jointly working on the problem analysis and formulation of ambitions [5].

\subsection{Pilots for 'Faster and Better' Decision-Making}

In light of the creation of a new Dutch Spatial Planning Act, two pilot projects on energy infrastructures were started in 2015 to implement the 'faster and better' decision-making process proposed by the Elverding advisory committee. Despite this new approach, several factors still limit the speed and quality of decision-making in energy projects, as identified by Kwast and Wesselink [24]. The main barriers are as follows. Firstly, a great many stakeholders with different objectives and tasks (investment, commissioning, control) are involved, but the different roles of these participants are not clear. Secondly, the set-up of projects is not being carefully established and properly thought through, and decision-making is not overarching and inclusive, but mainly takes place inside individual organisations. Thirdly, the identification and definition of projects often relates too much to their function (technology), which is especially the case for projects where distribution system operators (DSOs) are in charge and, for example, give priority to the security of supply. A last observation by Kwast and Wesselink [24] is the high external influence of the Ministry of Economic Affairs, 
even though no representative of the Ministry is directly involved in projects. Overall, 'faster and better' decision-making is not happening yet, which seems to derive mainly from a lack of clarity on tasks and roles in the decision-making process.

\subsection{Views of the Dutch Minister of Economic Affairs}

In 2016, the Dutch Minister of Economic Affairs recognised that the quality and speed of decision-making on energy infrastructures in the Netherlands have to increase in order to realise the energy transition [6]. However, the steps that are proposed for improving energy planning make us doubt whether this goal will be achieved. The Minister stresses that decision-making on energy projects should entail that stakeholders (citizens, companies, local governments, societal organisations, etc.) jointly identify public interests, and then formulate policies and projects based thereupon. He stresses the importance of involving potential stakeholders in the decision-making process as early as possible, and especially of ensuring their participation in finding solutions to the problem, and in selecting and narrowing down alternatives [6]. This priority of more and earlier participation in decision-making on energy projects is enshrined in the new Dutch Spatial Planning Act (Dutch: Omgevingswet) that will enter into force in 2019 [6].

The Ministry's document does not explain how earlier and intensified participation may accelerate processes and outcomes. We strongly doubt that the speed and quality of decision-making will increase by the changes suggested by the Ministry. We base this conclusion on four factors that, according to our analysis, overshadow Dutch practices of decision-making in energy planning and have been neglected in the Ministry's latest proposals to improve decision-making.

- Firstly, the consensus-based approach with a large amount of stakeholders slows down processes instead of speeding them up [5,6]. Involving more stakeholders in earlier phases of the process will complicate processes, simply due to the increase in voices and increased diversity among voices. The combination of diversity and consensus-orientation in particular holds the risk of longer decision-making and diluted outcomes.

- Secondly, the consensus-oriented decision-making process is likely to cause a loss of 'quality' for the final decision taken-if a decision is taken at all [6]. This is especially disadvantageous for innovative energy solutions, which are unlikely to be the most evident and feasible solution that the (vested interest) decision-making process offers [25].

- Thirdly, 'rules of the game' are lacking for the collaboration between stakeholders, which complicates and slows down decision-making [24]. If rules of the game are missing, different stakeholders with diverse perspectives, interests, and ambitions will probably need far more time to agree on anything at all.

- Finally, smart energy solutions are the outcome of an interest-oriented decision-process in the current practice, instead of a thoughtful activity to solve an identified problem, in this case the lack of sustainable energy infrastructure.

\subsection{Participation and Smart Energy Systems}

As shown, participation determines content through consensus-seeking by actors with vested interests in current practice, slowing down progress and leading to compromised outcomes. We argue that the quality of participation will be improved if participation becomes functional to achieving the most sustainable, smart energy system. Smart energy systems are highly complex systems that require the knowledge and expertise of experts to achieve the best and most sustainable design. Only at certain moments in time is the functional involvement of external stakeholders such as residents ever needed. The purpose of this involvement should not be to determine the detailed featuring of a smart energy system, as is currently the case, but to fine-tune and optimise the technical design of the expert.

In this article, we use the example of the smart energy system that was envisioned for the project 'Smart Grid MeppelEnergie', co-financed by the Dutch government for the period from 2012 to 2016 
via the Switch2SmartGrids tender. The main project partners were DSO Rendo, the municipality of Meppel, and regional energy supply company MeppelEnergie. The goal of the project was the installation of a hybrid smart energy system consisting of a district heating grid fed with biogas via a powered combined heat and power (CHP) plant. Additionally, individual heat pumps are to be placed in several dwellings in the area. The system becomes 'smart', i.e., balanced, in several ways. Firstly, the heat pumps turn on when heat supply is too low/demand is too high; as these heat pumps use electricity, the supply of electricity at these times has to be taken into account as well. Secondly, remote-control of electric vehicles, in-house appliances (e.g., smart washing machines), and the heat pumps will be used to balance electricity supply and demand. By the spring of 2017, these aims had however not been achieved; the district heating grid was powered with natural gas.

This example illustrates that smart energy systems are highly complex technical systems that involve a change to the current energy infrastructure, and thus require specific knowledge and expertise to be able to design such complex systems. It is neither fruitful nor efficient to involve non-experts such as residents in all steps of the technical design of a smart energy system. The involvement of residents is much more purposeful in providing feedback to fine-tune the technical design of experts, for example to co-design the most accepted options for the remote-control of household appliances. We believe that involving residents at specific moments during the technical design process-instead of not at all or through continuous co-design from the beginning-is more functional, will increase efficiency, and will lead to smart and sustainable outcomes faster.

In the next sections of this article, we will suggest an approach to rebalance efficiency and participation in decision-making on sustainable smart energy systems, guided by the principle that the content of the design should determine who participates how and when. We argue for a reorganisation of current decision-making practices to increase efficiency and thereby accelerate the design and implementation of smart energy systems. We make participation instrumental to achieving the most sustainable technological solutions for the Dutch energy system. As indicated in the introduction, our approach is inspired by the engineering design process, which is explained in more detail in the next section.

\section{Engineering Design as Inspiration}

Engineers transform problems systematically and step-by-step into technically designed solutions. In doing so, the engineering approach distinguishes between the designing activities and the activity of implementing the (socio-technical) design. We think the engineering approach provides inspiration to find ways to increase effectiveness and efficiency of decision-making in energy planning. Effectiveness concerns the realisation of sustainable energy ambitions. Efficiency is mainly related to a more functional and structured participation of stakeholders. This view on participation "stresses the functional role of participation as an instrumental tool", in which the ends of these functions can differ [26] (p. 6). Following this perspective for designing and implementing smart energy systems, participation has to be functional for achieving the most sustainable, smart solutions (which of course have to adhere to legitimacy and responsibility criteria).

\subsection{Rational Decision-Making}

The design and implementation of the functional approach of participation is facilitated by structured, rational decision-making. Herbert A. Simon is considered a pioneer of the study of rational decision-making in organisations [27]. To summarise, "Simon argues that rationality is essentially procedural, that is to say, it may be viewed as selection goals and course of action which will best achieve the values of purposes" [28] (p. 278). He refers to the ideal rational decision-model as that of the 'economic man', and contrasts it with that of the 'administrative man', who is subject to bounded rationality. While rationality is limited in practice, Simon advocates that it should always be the objective of decision-making. Following this line of thinking, a multitude of rational, phase-oriented models have been developed, often based on a policy cycle [29]. 
The rational decision-making model was criticised by Lindblom in his famous paper 'The science of muddling through' [30]. Lindblom refers to this rational model as the 'rational comprehensive approach' and sets it against the model of 'successive limited comparison'. Whereas the rational model entails the clarification of values or objectives, means-ends analysis, comprehensive analysis, and theoretical basis, 'successive limited comparison' takes the form of 'muddling through'. The latter incremental approach is, according to Lindblom, superior. A similar comparison is made by Allision [31] in 'Essence of Decision: Explaining the Cuban Missile Crisis', where he argues against the usefulness of the rational actor model in analysing decision-making by nation states. In line with this reasoning, several models and theories have been developed, based on the perspective of the 'administrative man' and emphasising the role of coalitions, goals, and interests. Well-known models are the garbage can theory [32], the multiple streams model [33], and the advocacy coalition framework [34].

These coalition and network-based approaches are based on a more coincidental coming together of actors, and do not provide structure regarding stakeholder involvement in decision-making. As explained in Section 2, these 'muddling through' approaches are neither effective nor efficient for realising the energy transition in the Netherlands. For smart energy systems-specific expertise in particular, input and agreements at particular points in time are needed to increase the efficiency and efficacy of decision-making. More recently, scholars have followed similar thinking for the design of technological systems and infrastructures, but mostly address the design of institutions [35] or how to align technical and economic designs [36], or only formulate general advice for co-design [37] or integrating an actor perspective [38]. Our approach, on the other hand, focuses on specific steps for functional stakeholder participation with the help of the engineering approach for technical design processes.

\subsection{From the Engineering Design Process to a Decision-Making Model}

For the development of a detailed decision-making model for smart energy systems, we take the abovementioned governance models in mind, but mostly take inspiration from the engineering design process. Pahl, Beitz, Feldhusen, and Grote [14] explain the distinction engineers make between a design and its implementation. The engineer analyses the problem, formulates a set of design principles (functionalities), creates possible design solutions, and only then starts working on the implementation of the design. The phases of this engineering design process can be summarised as follows:

1. task clarification;

2. requirements;

3. conceptual design (principle solution);

4. detailed design; and

5. implementation of the solution.

Task clarification starts after an external request or development order to the engineers. As we are interested in every step of the design process, we will add 'task definition' as the initial design activity, leading to six phases.

Looking at the entire process, we can distinguish between six design activities (what needs to be done when), design performers (who is in charge of each activity), and design products (what is the product/result of each activity), as summarised in Table 1 and explained below. 
Table 1. Design activities, performers, and products.

\begin{tabular}{cccc}
\hline Phase & Activity & Design Performer & Design Product \\
\hline 1 & Task definition & Problem owner & Problem definition \\
2 & Task clarification & Problem owner/expert & Task definition \\
3 & Requirements & Problem owner/expert & Design conditions \\
4 & Conceptual design & Expert & Technical options for smart energy system \\
5 & Detailed design & Expert & Detailed smart energy system design \\
6 & Implementation & Project manager & Realised infrastructure \\
\hline
\end{tabular}

In addition to the design performers, external stakeholders-actors aside from the core design performers-need to participate in certain phases of decision-making. The involvement of external stakeholders, such as residents, should not merely happen for the sake of involvement, but should be functional and purposeful to the outcome. While the design performers often need to possess expert knowledge and are deeply involved in the project, external stakeholders can contribute to certain parts of the project, e.g., by providing information on local needs, co-financing a storage facility or providing access to their smart meter data. This involvement can be structured by identifying specific moments for external stakeholder participation in the decision-making process and the kind of outcomes to be achieved as the result of those specific participation moments. Integrating these moments of participation with the components of design (Table 1) leads to Table 2. This table indicates the general positions of design performers and external participants, which are further determined by the specificity of individual projects. Note that the symbol ' $/$ ' in Table 2 means no involvement and that each position can be occupied by more than one actor. For example, a municipality and a housing association can be problem owners together. The results section of this article contains a specific example with detailed explanations on the involved actors as well as details on the content of each phase. A flowchart that summarises the steps in a different format can be found in Appendix A.

Table 2. Decision-making phases with design performers and external participants.

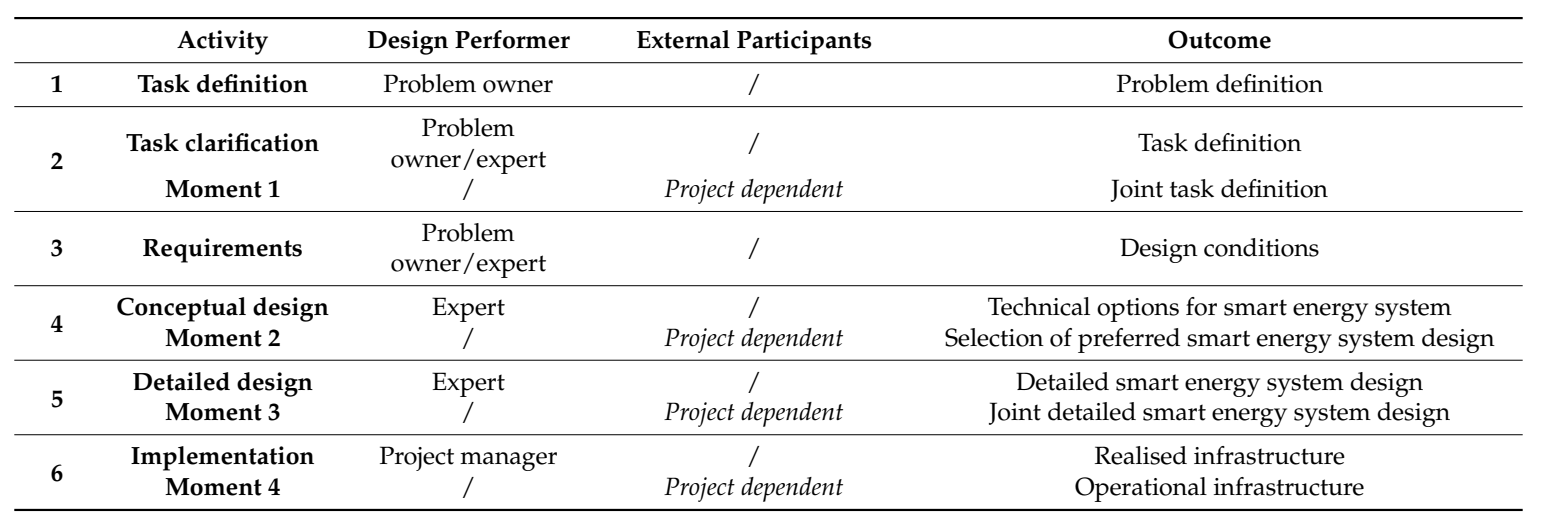

The moments for participation have been chosen based on the assumed functionality of the third party input in the different phases of the decision-making process. Along these lines, participation is conceived as a function of improving and fine-tuning the design of the expert. This is different from the current position of participation in energy planning, an inherent part of each step in the design process. Our approach implies participation by third parties prepared and structured by the activities and results of the expert designer. The input from external actors is useful for fine-tuning the technical design at several moments throughout the development process, and helps increase the acceptence and legitimacy of the design.

Phase 1 and 2, defining and clarifying tasks, are first and foremost the responsibility of problem owners, which are parties with law-based authority (e.g., a municipality or housing association) or with professional expertise (e.g., an energy supply company or DSO). Once the task has been clarified 
by the core design performers, input from external actors is useful. This way, a joint task definition can come about and initial public support can be created (participation moment 1). Defining the design requirements demands specific, professional expertise, e.g., mapping the technical, economic, environmental, legal, ethical, and political requirements of different design options. The same is the case for defining the technical options of the conceptual design. For the selection of the preferred smart energy system, input from external participants is once again very useful in order to collectively choose one option for further elaboration (participation moment 2).

The detailed design phase will elaborate on the chosen option, taking into account the feedback provided during participation moments 1 and 2. Stakeholders now get a clear idea of all the details of the technical design and its implications for energy usage. At this point (participation moment 3 ), they are able to provide input for final changes and modifications to the technical design. In moment 3 in particular, stakeholders are facilitated to provide informed and knowledgeable input for the final technical design.

After finishing the technical design using the structured input and involvement of stakeholders, the design needs to be implementated. Implementation is clearly distinguished from design. However, modifications of the design might be needed during implementation for practical or unforeseen reasons. For that and other reasons, the participation of external stakeholders during implementation is important. That being said, particpation should be functional to an effective outcome at this point, just like in the design process. Apart from this condition, it is not possible to specify participation during implementation in more detail, due to the uniqueness of implementation processes.

\section{Methodology}

To specify the content of the decision-making phases with a design component and participation component, an exploratory focus group session and a validation session were organised [39]. The exploratory focus group session took place on 8 May 2017. Participants discussed the statement 'accelerating smart technology implementation in the Dutch energy system requires reinventing participation to improve efficiency'. Seven participants joined this session due to their own interest in the topic: three employees from different DSOs, one member of an energy cooperative, and three researchers from the field of social science working at different universities. Based on this exploratory session, an initial proposal for the decision-making phases and content thereof was developed. On 19 May 2017, this proposal was presented to experts on smart energy system development for their feedback and fine-tuning in order to develop the most accurate and useful model. This validation session was attended by experts from an energy cooperative, an applied research institute, the Netherlands Standardisation Institute, as well as by a project developer for smart cities, and by researchers from the fields of electrical engineering, mathematics, and computer science working at different universities.

Whereas these focus group sessions provided important information and validation, the adopted methodology has its limitations in terms of the representativeness of stakeholders and the potential hesitation of participants to voice their opinions in front of others. Furthermore, the discussions are often broader than is the case with, for example, in-depth expert interviews. However, this broad feedback was exactly what we sought for fine-tuning our suggested approach.

\section{Results}

This section presents our suggestions to improve the efficacy and efficiency of the design and implementation of smart energy systems, as specified through the workshop sessions. Based on the engineering design process and the identification of specific participation moments described in Section 3, we lay out the six steps of balanced participatory decision-making on smart energy systems. We explain the steps in reference to the example introduced in Section 4, which is summarised in Table 3. The example chosen here is related to the project 'Smart Grid MeppelEnergie' described in Section 2.4. The project's compromised outcome makes this case an interesting one for exemplifying 
how the decision-making process could have been structured with the help of the decision-making model we developed.

Table 3. The decision-making model applied to a specific example.

\begin{tabular}{|c|c|c|c|c|}
\hline & Activity & Design Performer & External Participants & Outcome \\
\hline 1 & Task definition & Municipality (problem owner) & / & Problem definition \\
\hline \multirow[t]{2}{*}{2} & Task clarification & $\begin{array}{l}\text { Municipality (problem owner), } \\
\text { energy supply company (expert) }\end{array}$ & / & Task definition \\
\hline & Moment 1 & / & $\begin{array}{l}\text { Board of energy } \\
\text { cooperative }\end{array}$ & Joint task definition \\
\hline 3 & Requirements & $\begin{array}{l}\text { Municipality (problem owners), } \\
\text { energy supply company (expert), } \\
\text { consultation with DSO }\end{array}$ & / & Design conditions \\
\hline \multirow[t]{2}{*}{4} & Conceptual design & Energy supply company (expert) & / & $\begin{array}{l}\text { Technical options for smart } \\
\text { energy system }\end{array}$ \\
\hline & Moment 2 & / & $\begin{array}{l}\text { Members of energy } \\
\text { cooperative }\end{array}$ & $\begin{array}{l}\text { Selection of preferred smart } \\
\text { energy system design }\end{array}$ \\
\hline \multirow[t]{2}{*}{5} & Detailed design & Energy supply company (expert) & / & $\begin{array}{c}\text { Detailed smart energy system } \\
\text { design }\end{array}$ \\
\hline & Moment 3 & / & $\begin{array}{c}\text { All residents living in the } \\
\text { district }\end{array}$ & $\begin{array}{l}\text { Joint detailed smart energy } \\
\text { system design }\end{array}$ \\
\hline \multirow[t]{2}{*}{6} & Implementation & $\begin{array}{l}\text { Municipality and energy supply } \\
\text { company hire contractor (project } \\
\text { manager) for technical installation }\end{array}$ & / & Realised infrastructure \\
\hline & Moment 4 & / & $\begin{array}{c}\text { All residents living in the } \\
\text { district }\end{array}$ & Operational infrastructure \\
\hline
\end{tabular}

\subsection{Phase 1: Task Definition}

In this example, the task definition was undertaken by the problem owner, a municipality. The municipality had to be clear about the overall purpose of embarking on the project and the desired goals. National, regional, and local sustainable policy ambitions have been taken as reference points for the problem owner. If such policy ambitions as a project reference are missing at the local level, it might be advisable to clarify them first, before continuing further discussions. The board of a municipality might, for example, have the authority to set a sustainability target for a district (e.g., being energy-neutral in 2030, having to install a district heating grid). Task definition therefore can be very effective if it is the individual task of one or a small group of initiators (e.g., a municipality together with a housing association) in charge of conceptualising a sustainable smart energy system.

\subsection{Phase 2: Task Clarification and Participation Moment 1}

Like task definition, clarifying tasks is first and foremost the responsibility of problem owners. If the task is clear, external stakeholders can be consulted during the first moment of participation.

\subsubsection{Task Clarification}

After the task has been defined in general terms and the sustainability context and conditions have been set, the task has to be narrowed down and specified. Following the engineering design thinking of Pahl, Beitz, Feldhusen, and Grote [14] (p. 145), three questions are considered helpful for this specification:

- What are the objectives that the intended solution is expected to satisfy?

- What properties must it have?

- What properties must it not have?

In terms of the design performers, the problem owner first of all needs to clarify and specify its objectives. If a municipality wants to achieve an energy-neutral district by 2030, this goal has to be 
specified into, inter alia, a certain percentage of distributed generation from renewable sources or the amount of desired $\mathrm{CO}_{2}$ reduction. Additionally, the (municipal) budget and commitment should be established at this point, and specific deadlines and cost targets should be addressed for the project as a whole. This requires the involvement of experts from different disciplines, such as engineering, law, and innovation. In the chosen example, the municipality consulted a local energy supply company with expertise in renewable energy project development.

\subsubsection{Participation Moment 1}

After the municipality has specified the task in terms of the type and the dimensions of a sustainable smart energy system with the help of the energy supply company, it is useful to discuss the smart energy system idea with external stakeholders. If an energy cooperative of local residents exists, the board of this energy cooperative can be consulted in order to probe its view on the project, as the cooperative's members will most likely be directly involved in the energy system (e.g., allow the remote-control of their electric vehicle charging). The purpose of this first moment of participation is to come up with a joint task definition and to create general public support. Right from the beginning, it should be clear to participating stakeholders what kind of input is expected from them and how their input will be integrated in the task definition. This participation moment is intended to provide input on the pre-defined task definition; it is not an open invitation to brainstorm about smart energy system ideas and preferences.

\subsection{Phase 3: Requirements}

Specifying the exact shape of the project continues in the third phase, in which the specific requirements are established. Pahl, Beitz, Feldhusen, and Grote [14] (p. 150) recommend that engineers address four questions in order to come up with a detailed (technical) requirements list that states the goals and the circumstances under which these goals have to be met:

1. What is the problem about?

2. Which wishes and expectations are involved?

3. Which constraints exist?

4. What (technical) paths are open for development?

The final requirements can be quantitative or qualitative, and can take the form of either requirements or wishes. Additionally, the person responsible for each requirement should be listed. The resulting final list of requirements is referred to as the specific design conditions. Due to the rather technical nature of these design conditions, experts are, along with the problem owners, the main design performers in this phase. Experts like an energy supply company can delineate the specific technical conditions and constraints, as well as show which paths are (not) open for development. On the one hand, the experts developing the requirements list have to take into account the current situation, e.g., make an inventory of the energy consumption of residents in the area, the energy efficiency of buildings, and the state of the existing technical infrastructure. On the other hand, the focus group emphasised that the possible consequences of all technical design alternatives have to be considered at this point. This especially entails the consequences for grid infrastructure, be it electricity, gas, or heat infrastructure. For example, before installing heat pumps in each household of a city district, the responsible DSO must be consulted early on in the decision-making process in order to take into account (and ideally prevent) (un-)necessary investments in grid infrastructure.

Ideally, potential investors are identified and involved in this phase as well. Participation from external actors (non-experts) is not beneficial in this phase, as households, for example, do not have the expertise to choose which specific technical requirements and constraints certain smart meters need to have. The external participation component is relevant in the next phase when the design conditions lead to the creation of a conceptual design. 


\subsection{Phase 4: Conceptual Design and Participation Moment 2}

In the fourth phase, we are moving from design requirements to the identification of a conceptual design (also called principle solution). In engineering design thinking, this step "involves selecting preliminary materials, producing a rough dimensional layout, and considering technological possibilities" and explaining that "it is possible that there will be several principle solution variants" [14] (p. 131). For designing a smart energy system in this phase, the focus should lie on the overall feasibility of options. To investigate feasibility, we distinguish between the design stage and the participation stage.

\subsubsection{Conceptual Design}

For deciding which options of technical design alternatives are feasible, expertise is needed. Feasibility conventionally focuses on technical and financial feasibility, which are often investigated by developing a business model, or at least by conducting a cost-benefit analysis. Chesbrough and Rosenbloom [40] explain that "a successful business model creates a heuristic logic that connects technical potential with the realisation of economic value" (p. 529). However, next to technical and economic conditions, the environmental, legal, ethical, and political feasibility of options have to be evaluated as well for spatial projects that are concerned with the energy infrastructure (in residential areas). While an energy supply company is the design performer in this phase in our example, this company most likely will have to consult with other professional parties in order to obtain information on each type of feasibility.

\subsubsection{Participation Moment 2}

Out of the feasible technical options explored and suggested by the experts, one option needs to be chosen as the preferred design for the specific project. This is a good moment to involve stakeholders who might be affected by the smart energy system, for example the members of a local energy cooperative. This second moment of participation is structured and fed by the design options prepared by the expert. The problem owner (municipality), together with the expert (energy supply company) and external stakeholders (members of energy cooperative), should decide on the preferred design option that will be taken further in the design process. Participation during this second moment thus helps to select the most preferred option for the smart energy system design.

\subsection{Phase 5: Detailed Design and Participation Moment 3}

After the conceptual design comes the detailed design (also referred to as the embodiment design), linked to participation moment 3 .

\subsubsection{Detailed Design}

The detailed design is an additional and final specification of the conceptual design developed in phase 4. Following Reference [14], this includes, among other aspects, checking the functions, durability, operation, and costs, for which "technological and economic considerations are of paramount importance" (p. 227). While technical and financial feasibility have been investigated in phase 4, agreement about the actual financing of the selected options now needs to be reached and the safety of the design now needs to be secured. All of these aspects of the smart energy system have to be specified by experts. Once a detailed smart energy system design has been created, stakeholder involvement becomes functional for the final fine-tuning.

\subsubsection{Participation Moment 3}

The third moment for effective and productive interaction with stakeholders is in response to the expert's detailed design. During this third moment of participation, many stakeholders already know what to expect in terms of the smart energy system, since they were previously involved in 
selecting the preferred design. As a result, the discussion can at this point concentrate on the final fine-tuning of the smart energy system design. Ideally, all residents in the district where the project is taking place should assess the practical implications of the design on their daily life, for instance in terms of user-friendliness, economic practicalities, local culture and practices, learning requirements, and the outlook and landscape of the district. Final adjustments can then be made based on their input. To sum up, the problem owner, expert, and external stakeholders jointly decide on what the final, detailed design of the smart energy system will look like.

\subsection{Phase 6: Implementation and Participation Moment 4}

When the final design of the smart energy system is ready, implementation can start. During this implementation phase, design performers and external participants are closely connected.

\subsubsection{Implementation}

Due to the fact that the design of the smart energy system is the result of five thoughtful, detailed steps, all aspects of the technical design requiring implementation are clear. Implementation is no longer an act of designing and thinking, but of doing and acting. Implementation means organising processes and coordinating people and resources, i.e., project and process management. For this task, the expertise of a project manager as well as a process manager (see below) is especially beneficial. Apart from having a project manager's organising competences, this actor should also be a communicator, as the implementation phase requires a great deal of communication: communication between companies and organisations, with the project owner, the licencing authorities, and financial organisations, and last but not least with the future users of the smart energy system. Thus, stakeholder communication and management can be considered a core competence for the project manager.

\subsubsection{Participation Moment 4}

Implementation essentially means managing the participation and division of tasks between different agents, as indicated above. The participation of future users of the smart energy system (e.g., the residents in the district) needs to receive special attention and needs to be organised in a structured way throughout the whole implementation process. Fortunately, participants are very likely to be familiar with the project as they, or people they know (e.g., neighbours) were involved in earlier participation moments. Of course, implementation has and can have its own dynamics in the Netherlands, due to unforeseen financial, legal, or social circumstances and setbacks during activities (bankruptcy of companies for instance). However, from a participatory perspective, continued open communication with stakeholders is very important. Discussion of the modes of communication even before implementation could be a good start; for example, a communication platform could be established with the help of modern communication technology.

\subsection{Summary}

To summarise, we distinguish between six phases in the planning process during which design performers and external stakeholders are invited to functionally participate in the decision-making process. This practice is the basis for a more effective and more efficient planning process for the realisation of new smart renewable energy infrastructures. As the suggested structured decision-making process identifies roles and positions instead of specifying specific actors, the process can be applied to a wide variety of energy planning situations. Besides the example used here with a Dutch municipality as the problem owner, smart energy infrastructure projects can be initiated by a wide variety of actors under the current Dutch energy planning practice depending on the context, ranging from energy cooperatives and housing associations to DSOs.

Based on the focus group sessions and following References [41-43], we recommend involving a process architect and later a process manager or network manager in the decision-making process. A process manager is especially needed during implementation, but can also help during earlier 
phases with structuring and facilitating the design activities and participation moments. At the beginning of each of the six design phases, a process manager could help the design performers set goals and deadlines and ensure that actors stay on track and stick to the agreements that are made. For the participation moments, a process manager's tasks additionally include practical aspects like inviting participants, arranging meeting locations, compiling the agenda, and moderating discussions. This streamlining can eventually increase the speed of decision-making even more.

\section{Discussion and Conclusions}

In this article, we presented a decision-making model for local energy planning by addressing the question 'how can decision-making on the design and implementation of smart energy systems be accelerated?' Whereas more and early participation of any stakeholders compromises the degree of sustainability of the results and slows down progress under the current practice, we emphasise the functional participation of actors in order to increase efficacy and efficiency. Inspired by the engineering design process and based on workshops, we identified a design component and a participation component for six phases of the decision-making process: (1) task definition; (2) task clarification and participation moment 1; (3) requirements; (4) conceptual design and participation moment 2; (5) detailed design and participation moment 3; (6) implementation and participation moment 4. Sticking to this process provides clarity on actors' tasks and roles and facilitates more functional and therefore more efficient participatory decision-making.

Overall, this article provides a new governance perspective on the design and implementation of technical smart energy systems. The new governance approach is based on functional external participation in a technically oriented design process conducted by professionals. Due to several reasons, we consider the developed approach helpful for accelerating the implementation of smart energy systems without affecting the content and role of public participation. First, our approach structures and prepares participation more specifically compared to current governance practices in energy planning in the Netherlands. Second, it clarifies positions and expectations in energy design and implementation processes up front. This clarification is becoming more important in the ever more diffuse setting of new energy infrastructure planning in the Netherlands. Third, our approach rebalances participation and effective, sustainable outcomes of energy planning in the Netherlands, as it can prevent vested interests from watering down sustainability outcomes. Fourth, the suggested approach can facilitate the collaboration of practitioners during the design and implementation of smart energy systems in a wide range of contexts, including the upgrading of existing infrastructures and the development of new ones. Lastly, the focus on the entire decision-making process provides an overarching approach that goes beyond individual aspects of renewable energy system implementation, but can also encompass aspects such as end-user involvement [20], domestic energy practices [44], and public acceptance [21].

We realise that the advantages of our suggested repositioning of participation in energy planning processes needs empirical validation. Empirical research can also discover disadvantages of energy planning with sharper distinction between professional experts developing the technical design and the stakeholder providing input for optimising the design. It might be that stakeholders are unhappy with such a repositioning of roles and positions in the design process of a smart energy system. It is unclear what the consequences for process evolution and the outcome will be. We believe that with a clear explanation, our decision-making model can convince stakeholders of the significance and importance of their role as design optimisers. However, we also realise that problem owners and professional experts need to position themselves accordingly vis-à-vis external stakeholders. If problem owners and professionals act differently, situations of distrust might occur, which can be very harmful for open effective decision-making in energy infrastructure planning. An important next step in research, therefore, would be to empirically compare energy planning settings in the Netherlands with conventional participation to a project in which our suggested functional participation approach is applied. This might illustrate the assumed advantages of the functional participatory approach we 
described in this paper. This kind of knowledge will help to convince problem owners, professional designers, and stakeholders to work together in the common interest of achieving optimal sustainability in the planning of smart energy systems.

Acknowledgments: This work was supported by the Netherlands Organisation for Scientific Research (NWO), under the URSES project SmaRds (project number 408-13-005). The authors would like to thank the two independent reviewers as well as Thomas Hoppe and Michiel A. Heldeweg for their helpful comments and suggestions.

Author Contributions: Both authors contributed equally to this publication.

Conflicts of Interest: The authors declare no conflict of interest.

\section{Appendix A}

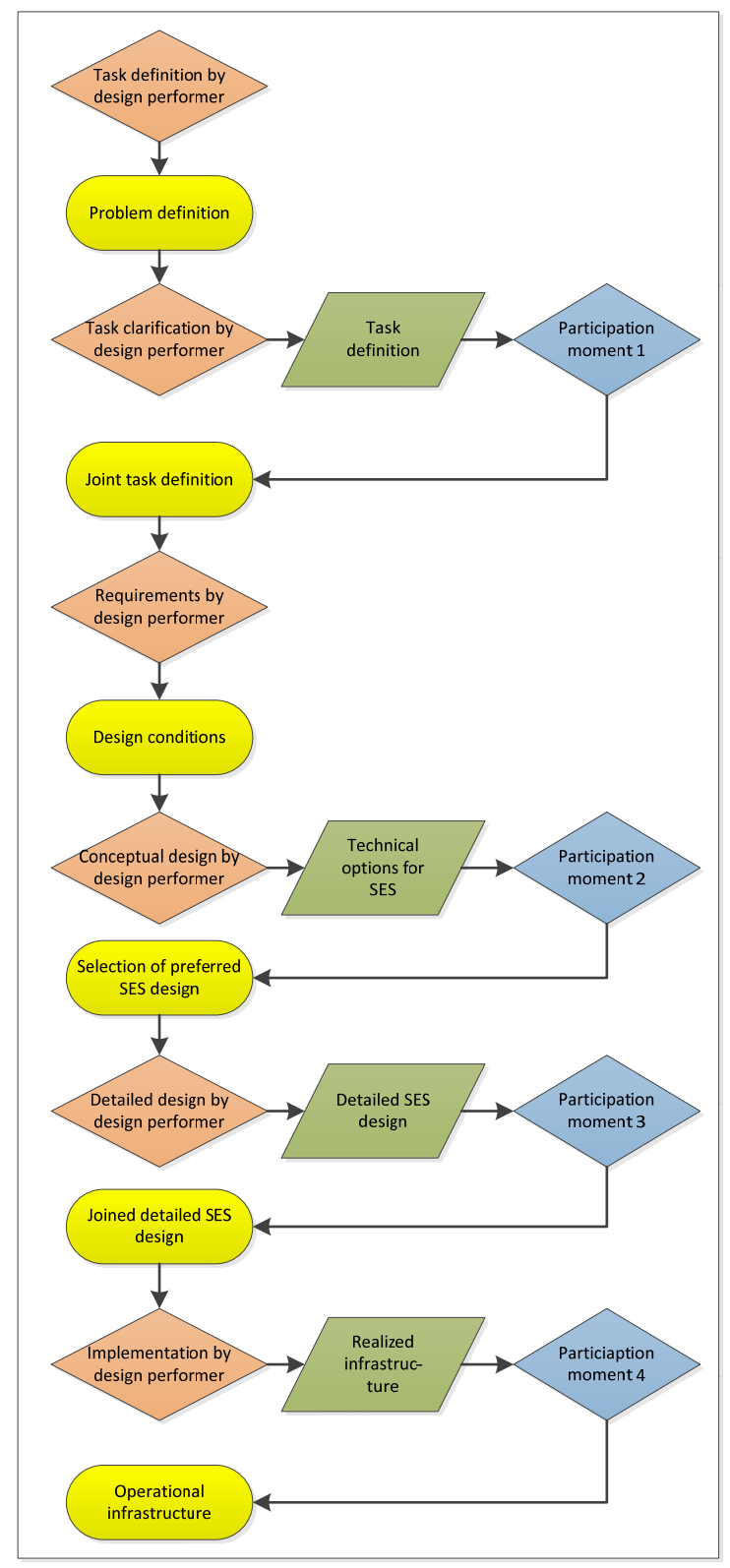

Figure A1. Flowchart for the decision-making model.

Note that the abbreviation SES in Figure A1 stands for smart energy system. 


\section{References}

1. Ministerie van Economische Zaken. Op weg Naar Intelligente Netten in Nederland_Einddocument van de Taskforce voor Intelligente Netten; Ministerie van Economische Zaken: Den Haag, The Netherlands, 2011.

2. Ecofys. Waarde van Slimme Netten: Welke Waarde Creëren Slimme Oplossingen in Het Distributienetwerk? Ecofys: Utrecht, The Netherlands, 2014.

3. Blumsack, S.; Fernandez, A. Ready or not, here comes the smart grid! Energy 2012, 37, 61-68. [CrossRef]

4. Lund, H.; Werner, S.; Wiltshire, R.; Svendsen, S.; Thorsen, J.E.; Hvelplund, F.; Mathiesen, B.V. 4th Generation District Heating (4GDH): Integrating smart thermal grids into future sustainable energy systems. Energy 2014, 68, 1-11. [CrossRef]

5. Commissie Elverding. Sneller en Beter: Advies Commissie Versnelling Besluitvorming Infrastructurele Projecten. Available online: https://www.rijksoverheid.nl/documenten/rapporten/2008/04/21/hetadvies-van-de-commissie-versnelling-besluitvorming-infrastructurele-projecten (accessed on 5 April 2017).

6. Ministerie van Economische Zaken. Samen Energieprojecten Realiseren: Visie op Omgevingsmanagement; Ministerie van Economische Zaken: Den Haag, The Netherlands, 2016.

7. Stamatescu, I.; Arghira, N.; Făgărăşan, I.; Stamatescu, G.; Iliescu, S.; Calofir, V. Decision Support System for a Low Voltage Renewable Energy System. Energies 2017, 10, 118. [CrossRef]

8. An, K.; Liu, H.; Zhu, H.; Dong, Z.; Hur, K. Evaluation of Conservation Voltage Reduction with Analytic Hierarchy Process: A Decision Support Framework in Grid Operations Planning. Energies 2016, 9, 1074. [CrossRef]

9. Chang, C.-L.; Chih-Hsien Peng, J. A Decision-Making Auction Algorithm for Demand Response in Microgrids. IEEE Trans. Smart Grid 2016. [CrossRef]

10. Ou, T.-C.; Hong, C.-M. Dynamic operation and control of microgrid hybrid power systems. Energy 2014, 66, 314-323. [CrossRef]

11. CENCENELEC. Smart Grid Reference Architecture; CEN-CENELEC-ETSI Smart Grid Coordination Group: Brussels, Belgium, 2012.

12. Choi, B.-E.; Shin, J.-H.; Lee, J.-H.; Kim, S.-S.; Cho, Y.-H. Development of Decision Support Process for Building Energy Conservation Measures and Economic Analysis. Energies 2017, 10, 324. [CrossRef]

13. Magrassi, F.; Del Borghi, A.; Gallo, M.; Strazza, C.; Robba, M. Optimal Planning of Sustainable Buildings: Integration of Life Cycle Assessment and Optimization in a Decision Support System (DSS). Energies 2016, 9, 490. [CrossRef]

14. Pahl, G.; Beitz, W.; Feldhusen, J.; Grote, K.H. Engineering Design: A Systematic Approach, 3rd ed.; Springer: London, UK, 2007.

15. Künneke, R.W.; Finger, M. The governance of infrastructures as common pool resources. In Proceedings of the Workshop on the Workshop (WOW4), Bloomington, IN, USA, 2-7 June 2009.

16. Elle, M.; Van Hoorn, T.; Moss, T.; Slob, A.; Vermeulen, W.; Van der Waals, J.F.M. Rethinking Local Housing Policies and Energy Planning: The Importance of Contextual Dynamics. Built Environ. 2002, 28, 46-56.

17. Arentsen, M.J.; Bellekom, A.A. Power to the people: Local energy initiatives as seedbeds of innovation? Energy Sustain. Soc. 2014, 4, 1-12. [CrossRef]

18. Heldeweg, M.A. Legal regimes for experimenting with cleaner production-Especially in sustainable energy. J. Clean. Prod. 2016, 169, 48-60. [CrossRef]

19. Lammers, I.; Diestelmeier, L. Experimenting with Law and Governance for Decentralized Electricity Systems: Adjusting Regulation to Reality? Sustainability 2017, 9, 212. [CrossRef]

20. Verbong, G.P.J.; Beemsterboer, S.; Sengers, F. Smart grids or smart users? Involving users in developing a low carbon electricity economy. Energy Policy 2013, 52, 117-125. [CrossRef]

21. Wolsink, M. The research agenda on social acceptance of distributed generation in smart grids: Renewable as common pool resources. Renew. Sustain. Energy Rev. 2012, 16, 822-835. [CrossRef]

22. Coenen, F.H.J.M.; Van De Peppel, R.A.; Woltjer, J. De evolutie van inspraak in de Nederlandse planning. Beleidswetenschap 2001, 15, 313-332.

23. European Commission. Report from the Commission to the European Parliament, the Council, the European Economic and Social Committee and the Committee of the Regions: Renewable Energy Progress Report; European Commission: Brussels, Belgium, 2017. 
24. Kwast, O.; Wesselink, M. Voor Energie \& Omgeving: Strategisch Mangement van Energieprojecten Onder de Omgevingswet; WesselinkVanZijst: Rotterdam, The Netherlands, 2016.

25. Hoppe, T. Adoption of innovative energy systems in social housing: Lessons from eight large-scale renovation projects in The Netherlands. Energy Policy 2012, 51, 791-801. [CrossRef]

26. Coenen, F.H.J.M. Introduction. In Public Participation and Better Environmental Decisions: The Promise and Limits of Participatory Processes for the Quality of Environmentally Related Decision-Making; Coenen, F.H.J.M., Ed.; Springer: New York, NY, USA, 2009; pp. 1-19.

27. Simon, H.A. Administrative Behaviour; Macmillan Publishers: New York, NY, USA, 1947.

28. Parsons, W. Public Policy: An Introduction to the Theory and Practice of Policy Analysis; Edward Elgar Publishing: Cheltenham, UK, 1995.

29. Hoogerwerf, A. Het Ontwerpen van Beleid: Een Handleiding Voor de Praktijk en Resultaten van Onderzoek, 2nd ed.; Kluwer: Alphen aan den Rijn, The Netherlands, 1998.

30. Lindblom, C.E. The Science of "Muddling Through". Public Admin. Rev. 1959, 19, 79-88. [CrossRef]

31. Allison, G.T. Essence of Decision: Explaining the Cuban Missile Crisis; Little, Brown and Company: Boston, MA, USA, 1971.

32. Cohen, M.D.; March, J.G.; Olsen, J.P. A Garbage Can Model of Organizational Choice. Admin. Sci. Q. 1972, 17, 1-25. [CrossRef]

33. Kingdon, J.W. Agendas, Alternatives and Public Policies; Little, Brown and Company: Boston, MA, USA, 1984.

34. Sabatier, P.A. An advocacy coalition framework of policy change and the role of policy-oriented learning therein. Policy Sci. 1988, 21, 129-168. [CrossRef]

35. Koppenjan, J.; Groenewegen, J. Institutional design for complex technological systems. Int. J. Technol. Policy Manag. 2005, 5, 240-257. [CrossRef]

36. Scholten, D.; Künneke, R. Towards the Comprehensive Design of Energy Infrastructures. Sustainability 2016, 8, 1291. [CrossRef]

37. Schot, J.; Rip, A. The past and future of constructive technology assessment. Technol. Forecast.Soc. Chang. 1997, 54, 251-268. [CrossRef]

38. Herder, P.M.; Bouwmans, I.; Dijkema, G.P.J.; Stikkelman, R.M.; Weijnen, M.P.C. Designing infrastructures using a complex systems perspective. J. Des. Res. 2008, 7. [CrossRef]

39. Oates, C. Research Training for Social Scientists; SAGE Publications Ltd.: London, UK, 2000.

40. Chesbrough, H.; Rosenbloom, R.S. The role of the business model in capturing value from innovation: Evidence from Xerox Corporation's technology spin-off companies. Ind. Corp. Chang. 2002, 11, 529-555. [CrossRef]

41. Kickert, W.J.M.; Klijn, E.-H.; Koppenjan, J.F.M. (Eds.) Managing Complex Networks: Strategies for the Public Sector; SAGE Publications Ltd.: London, UK, 1997.

42. Hoppe, T.; Graf, A.; Warbroek, B.; Lammers, I.; Lepping, I. Local Governments Supporting Local Energy Initiatives: Lessons from the Best Practices of Saerbeck (Germany) and Lochem (The Netherlands). Sustainability 2015, 7, 1900-1931. [CrossRef]

43. Bruijn, H.; Ten Heuvelhof, E.; In'T Veld, R. Process Management: Why Project Management Fails in Complex Decision Making Processes; Springer: Berlin, Germany, 2003.

44. Naus, J.; Spaargaren, G.; Van Vliet, B.J.M.; Van der Horst, H.M. Smart grids, information flows and emerging domestic energy practices. Energy Policy 2014, 68, 436-446. [CrossRef]

(C) 2017 by the authors. Licensee MDPI, Basel, Switzerland. This article is an open access article distributed under the terms and conditions of the Creative Commons Attribution (CC BY) license (http://creativecommons.org/licenses/by/4.0/). 